\title{
Identification of Histidine-Rich Glycoprotein in Human Colostrum and Milk
}

\author{
T. WILLIAM HUTCHENS, TAI-TUNG YIP, AND WILLIAM T. MORGAN \\ USDA/ARS Children's Nutrition Research Center, Department of Pediatrics, Baylor College of Medicine and \\ Texas Children's Hospital, Houston, Texas 77030 [T.W.H., T-T.Y.], and Division of Biochemistry and \\ Molecular Biology, University of Missouri-Kansas City, Kansas City, Missouri 64110-2499 [W.T.M.]
}

\begin{abstract}
Histidine-rich glycoprotein (HRG) is a 74$\mathrm{kD}$ glycoprotein, originally discovered in plasma, which contains an unusually large amount of histidine $(13 \mathrm{~mol} \%)$ and proline $(13 \mathrm{~mol} \%)$. The specific functions of this protein remain unclear, although it binds (reversibly) transition metal ions such as $\mathrm{Cu}$ (II) and $\mathrm{Zn}$ (II) with high capacity (10-13 equivalent) and moderate to high affinity $\left(\mathrm{k}_{\mathrm{d}}=0.2-10 \mu \mathrm{M}\right)$. Because the bioavailability of $\mathrm{Cu}(\mathrm{II})$ and $\mathrm{Zn}(\mathrm{II})$ ions in human milk is high, we have used specific antibodies from polyclonal antisera directed against purified human plasma HRG to investigate whether this or a related protein is a component of human colostrum and(or) mature milk. Fresh human colostrum (d 1-3) and milk (d 4-120) were collected in the presence and absence of multiple protease inhibitors and EDTA. Immuno "dot" blot analyses and ELISA were developed; HRG was present in both colostrum $(0.13-10 \mu \mathrm{g} / \mathrm{mL})$ and mature milk (0.1-10 $\mu \mathrm{g} / \mathrm{mL})$. Unidentified components in colostrum and milk, however, were found to depress HRG antigenicity in these assays. Western transfer and immunoblots of denatured colostrum and milk samples analyzed by SDS-PAGE revealed the presence of an immunoreactive band at $74-78 \mathrm{kD}$, with other bands at 47 and $24 \mathrm{kD}$ under both reducing and nonreducing conditions; smaller immunoreactive fragments $(12-14 \mathrm{kD})$ were detected in some samples. We observed at least one additional band of immunoreactivity of greater molecular mass $(>110 \mathrm{kD})$ in colostrum under nonreducing conditions; we did not observe these bands in plasma samples. Immunoaffinity and $\mathrm{Zn}$ (II) affinity isolation of HRG from colostrum and milk resulted in the copurification of several associated proteins. Nterminal amino acid sequence analysis of the isolated 74$\mathrm{kD}$ immunoreactive protein provided further evidence for identification as intact HRG; 13 of the first 15 residues were identical. These results demonstrate the presence of HRG, or a structurally related protein, in human colostrum and milk. (Pediatr Res 31: 239-246, 1992)
\end{abstract}

\section{Abbreviations}

HRG, histidine-rich glycoprotein PMSF, phenylmethylsulfonyl fluoride

TPCK, toluenesulfonylphenylalanine chloromethylketone TED, tris(carboxymethyl)ethylenediamine PAGGE, polyacrylamide gradient gel electrophoresis

Received April 26, 1991; accepted October 7, 1991

Correspondence and reprint requests: T. William Hutchens, Department of Pediatrics (CNRC), Baylor College of Medicine, 1100 Bates, Houston, TX 77030.

Funded, in part, with federal funds from the U.S. Department of Agriculture, Agricultural Research Service under Cooperative Agreement number 58-6250-1003 . The contents of this publication do not necessarily reflect the views or policies of the U.S. Department of Agriculture, nor does mention of trade names, commercial products, or organizations imply endorsement by the U.S. Government. Supported in part by NIH Grant No. HL37570 (W.T.M.).
Understanding the biology and function of trace elements in human milk must include the identification of specific human milk peptides and proteins that influence metal ion transport (bioavailability) and storage in the mammary gland during lactogenesis, as well as in the gastrointestinal tract of breast-fed infants. Equally important, in our view, is the need to understand the role of transition metal ions in the regulation of milk protein structure, bioavailability, and function. Much can be learned from existing knowledge of the transport and use of transition metal ions by serum proteins. For example, in several species, including humans, many of the proteins in maternal serum, particularly the metal-binding proteins, are similar or identical to the whey proteins in colostrum $(1,2)$.

Adult human serum contains a protein discovered in 1972 (3) referred to as histidine-rich glycoprotein. ${ }^{1}$ HRG is a $74-\mathrm{kD}$ glycoprotein that contains significant quantities of both histidine (13\%) and proline (13\%) (4), which are concentrated primarily in the C-terminal half of the molecule (4). Although HRG is known to interact with a variety of organic ligands and proteins (heme, heparin, plasmin, plasminogen, thrombospondin, and platelets) (5-13), its unique histidine content and primary structure suggest that it may affect metal ion transport. The large number of histidyl residues in the C-terminal proline-rich region suggests that many of the histidyl groups in this polyproline II helical section (8) are exposed to the aqueous environment at the protein's surface (14). The affinity of surface-exposed histidyl residues for transition metal ions has been well documented (15, 16). Indeed, HRG has been shown to bind up to 12-g atoms of divalent metal cations per mol of protein with an affinity $\left(\mathrm{k}_{\mathrm{d}}=\right.$ $0.2-10 \mu \mathrm{M})$ expected for a metal ion transport or storage protein $(5,8,17,18)$. The competition between HRG and other serum proteins for $\mathrm{Zn}(\mathrm{II})$ and $\mathrm{Cu}(\mathrm{II})$ is readily apparent in vitro (18).

Variations in maternal serum levels of HRG during pregnancy and early lactogenesis suggest that $H R G$ is specifically involved in both of these developmental processes. Although the plasma levels of HRG in adult males and nonpregnant females are similar $(\sim 100-130 \mu \mathrm{g} / \mathrm{mL})$, pregnant women $($ e.g. $8-12 \mathrm{wk})$ have significantly depressed levels of serum HRG. At parturition, maternal serum levels of $\mathrm{HRG}$ are reduced to approximately one third of the normal level (19-21). The concentrations of HRG in infant cord sera have been determined during late gestation. Infant serum levels of $\mathrm{HRG}$, in contrast to maternal serum levels, increase from approximately $18 \mu \mathrm{g} / \mathrm{mL}$ to greater than $40 \mu \mathrm{g} /$ $\mathrm{mL}$ during the last 4 to $6 \mathrm{wk}$ of gestation $(19,22)$. The decrease in maternal plasma levels of HRG and the increased concentration of this protein in infant serum during the last trimester of gestation corresponds to that period when delivery of $\mathrm{Cu}(\mathrm{II})$ and $\mathrm{Zn}(\mathrm{II})$ ions to the fetus is maximal $(23,24)$.

${ }^{1} \mathrm{HRG}$ has also been referred to as histidine-proline-rich glycoprotein (HPRG) to reflect its notably high concentration of proline residues. 
Although significant progress has been made in recent years to determine those specific components and mechanism(s) responsible for the superior metal ion bioavailability from human milk (25-30), this work remains incomplete. The present investigation was undertaken to determine whether human colostrum and milk contained the unique metal-binding protein $H R G$.

\section{MATERIALS AND METHODS}

Human colostrum was provided by the Children's Nutrition Research Center Human Milk Bank, Department of Pediatrics, Baylor College of Medicine, Houston, TX. Colostrum was collected before d 3 postpartum, and mature milk was collected from d 4 to 120 . Samples were collected in both the presence and absence of the protease inhibitors aprotinin $(100 \mu \mathrm{g} / \mathrm{mL})$, soybean trypsin inhibitor $(50 \mu \mathrm{g} / \mathrm{mL})$, leupeptin $(50 \mu \mathrm{g} / \mathrm{mL})$, benzamidine (1 mM), PMSF $(0.4 \mathrm{mM})$, or TPCK $(10 \mu \mathrm{M})$ and EDTA $(10 \mathrm{mM})$ and stored at -20 or $-80^{\circ} \mathrm{C}$ until use.

Preparation of colostrum and milk for HRG analyses. Human colostrum and milk samples were thawed and centrifuged at $10000 \times g$ for $15 \mathrm{~min}$ at $4^{\circ} \mathrm{C}$ to remove the lipid layer.

Preparation of antisera and purified Ig specific for $H R G$. Antisera against purified preparations of human serum HRG were prepared in both goats and rabbits by multiple injections (50 $\mu \mathrm{g}$ each) in Freund's incomplete adjuvant over a 3-mo period. The Ig from portions of the HRG antisera were purified by thiophilic adsorption (31) and immunoaffinity adsorption on immobilized HRG purified from human plasma.

Immuno "dot" blot analyses. Immuno dot blots were performed using a microfiltration Bio-Dot apparatus and procedures provided by Bio-Rad Laboratories (Richmond, CA). Nitrocellulose membranes (Bio-Rad) were used to bind the antigen in (100$\mu \mathrm{L})$ samples of human colostrum, milk, plasma, or control protein (purified human serum HRG) and then were blocked with either 3\% (wt/vol) BSA (Sigma Chemical Co., St: Louis, $\mathrm{MO}$ ) or $0.1 \%$ (wt/vol) horse skeletal muscle myoglobin (Sigma). The antigen was exposed to primary antibody (purified antibodies reconstituted to approximately $1 \mathrm{mg} / \mathrm{mL}$ ), then either an alkaline phosphatase-conjugated secondary antibody (goat antirabbit IgG heavy and light chain; Kirkegaard and Perry, Gaithersburg, MD) or a gold-conjugated secondary antibody (goat anti-rabbit IgG, Auroprobe; Amersham, Arlington Heights, IL) was incubated with the membrane according to the manufacturer's instructions. Color development for the alkaline phosphatase-conjugated complexes was initiated by the addition of the 5-bromo-4-chloro-3-indolyl-phosphate/nitroblue tetrazolium phosphatase substrate system from Kirkegaard and Perry. In the case of the gold-conjugated antibody, color development was completed by use of the Intense BL silver enhancement kit from Amersham.

Electrophoretic (Western) transfer and immunoblotting. SDSPAGGE (10-20\% total acrylamide, 3\% bisacrylamide crosslinker) and immunoblots were performed under denaturing conditions as described recently (32), except that reducing agents (3\% mercaptoethanol) were eliminated during sample preparation as indicated. Western transfer was performed on nitrocellulose membranes (Bio-Rad) at $\mathrm{pH} 8.3$ in $0.025 \mathrm{M}$ Tris, $0.19 \mathrm{M}$ glycine, $12 \%$ methanol buffer at $150 \mathrm{~V}$ for $2 \mathrm{~h}$ at $4^{\circ} \mathrm{C}$. The nitrocellulose membranes were blocked for $1.5 \mathrm{~h}$ at $37^{\circ} \mathrm{C}$ with $3 \%$ BSA (Sigma) in $5 \mathrm{mM}$ Tris- $\mathrm{HCl}, 0.15 \mathrm{M}$ sodium chloride, $\mathrm{pH}$ 8.0. After blocking, the membrane was incubated for $1.5 \mathrm{~h}$ at $37^{\circ} \mathrm{C}$ with goat or rabbit anti-human $\mathrm{HRG}$ primary antibodies (affinity-purified Ig fraction) diluted in $5 \mathrm{mM}$ Tris- $\mathrm{HCl}(\mathrm{pH} 8.0)$, $0.15 \mathrm{M} \mathrm{NaCl}$, and $0.05 \%$ Tween-20. After incubation with the primary antibody, the membrane was incubated for $1.5 \mathrm{~h}$ at $37^{\circ} \mathrm{C}$. with diluted rabbit anti-goat IgG antibodies conjugated with alkaline phosphatase (Bio-Rad) or goat anti-rabbit IgG antibodies conjugated with either gold (Amersham), alkaline phosphatase (Kirkegaard and Perry), or horseradish peroxidase (Bio-Rad). A more sensitive method of detection was by en- hanced chemiluminescence. Horseradish peroxidase, conjugated to the secondary antibody, was used to catalyze the oxidation of a luminol detection reagent (Amersham) in the presence of hydrogen peroxide. Light emitted by the oxidized luminol was detected by autoradiography (Kodak X-OMAT AR5) in a film cassette fitted with Dupont Cronex Lightning Plus intensifying screen.

Quantitative determination of $H R G$ concentration. HRG concentrations were determined semiquantitatively by Western transfer and quantitatively by ELISA methods. Polyclonal goat antibodies or rabbit antibodies directed against human serum HRG were first purified by thiophilic adsorption (31) and then by immunoadsorption affinity chromatography. Radial immunodiffusion was performed on $1 \%$ agarose plates with $1: 1000$ diluted rabbit anti-human $\mathrm{HRG}$ in $10 \mathrm{mM}$ veronal buffer $\mathrm{pH}$ 8.6 and $3 \%$ polyethylene glycol (PEG 6000). Several dilutions of standard human serum HRG and samples to be evaluated for HRG were applied to the plate in duplicate. The plate was placed in a moist chamber at room temperature for 2-3 d until sharply delineated precipitin rings were observed. The ELISA was performed with purified anti-human HRG antibodies immobilized in the wells of 96-well polystyrene microtiter plates (Corning Science Products, Corning, NY). The samples were first incubated $\left(22-25^{\circ} \mathrm{C}\right.$ for $\left.18 \mathrm{~h}\right)$ with the primary immobilized antibody. The plates were then washed with Dulbecco's PBS (Sigma) containing $0.05 \%$ Tween-20 (Sigma) before incubation with a second antibody (rabbit anti-HRG) conjugated to horseradish peroxidase. The color reaction was developed with hydrogen peroxide in citrate buffer containing $o$-phenylenediamine (Sigma). After the reaction was stopped with sulfuric acid, color intensity at $490 \mathrm{~nm}$ was measured.

Immobilization of purified anti-HRG antibodies and affinity isolation of human milk HRG. Purified human plasma HRG was immobilized on divinylsulfone-activated agarose (31) to purify $H R G$ antibodies from the serum of $H R G$-immunized rabbits. The purified anti-HRG antibodies were recovered and immobilized on divinylsulfone-activated agarose to purify HRG from human colostrum and milk. Samples of colostrum and milk (taken up to the 120 th $\mathrm{d}$ of lactation) were diluted with 1 volume of the affinity gel equilibration buffer $(20 \mathrm{mM}$ sodium phosphate, $0.5 \mathrm{M} \mathrm{NaCl}, \mathrm{pH} 7.0$ ) and passed slowly over a 12$\mathrm{mL}$ column $(2.8 \mathrm{~cm}$ inner diameter $\times 2 \mathrm{~cm})$ of anti-HRG affinity gel at least four times at $25^{\circ} \mathrm{C}$. Unbound and loosely bound proteins were removed by washing ( $>5$ column volumes) with 1) column equilibration buffer, 2) column equilibration buffer containing $3 \mathrm{M}$ urea, 3) column equilibration buffer containing $25 \%$ (by volume) ethylene glycol, and 4) column equilibration buffer containing $2.5 \mathrm{M} \mathrm{NaCl}$. Bound $\mathrm{HRG}$ was eluted with 0.1 $\mathrm{M}$ glycine- $\mathrm{HCl}, \mathrm{pH} 2.5$, followed by $2 \mathrm{M}$ sodium thiocyanate adjusted to $\mathrm{pH} 7$ with $50 \mathrm{mM}$ sodium phosphate. To estimate the quantities of recovered $H R G$, we performed parallel experiments in which trace quantities of ${ }^{125} \mathrm{I}$-labeled human plasma HRG were added to the colostrum and milk samples before affinity isolation. All column eluents were evaluated for protein composition and HRG immunoreactivity by SDS-PAGGE and immunoblotting.

Solid-phase microsequence analyses from immunoblots. Nterminal amino acid sequences of isolated $\mathrm{HRG}$ were determined by the Edman degradation method with an Applied Biosystems model 473A automated peptide sequence analyzer (Applied Biosystems, Foster City, CA). HRG was partially purified on affinity columns of immobilized anti-HRG antibodies or immobilized TED-Zn(II) ions (33). All affinity columns (including the tubing) were previously unused to eliminate the possibility of HRG contamination. After SDS-PAGE on an $8 \%$ acrylamide gel, samples were electroblotted $(75 \mathrm{~V}$ constant voltage for $3 \mathrm{~h}$ at $4^{\circ} \mathrm{C}$ ) onto a Problott polyvinylidinedifluoride membrane (Applied Biosystems) in $10 \mathrm{mM}$ CAPS (3-[cyclohexylamino]-1-propanesulfonic acid) buffer ( $\mathrm{pH} 11.0$ ) containing $10 \%$ methanol, then stained with $0.1 \%$ Coomassie blue R-250 in $40 \%$ methanol/ 
$1 \%$ glacial acetic acid for 1 to $1.5 \mathrm{~min}$. The membrane was then destained with $50 \%$ methanol, washed extensively with Milli-Q water (Millipore, Bedford, MA), and dried overnight; the bands of interest were excised for sequencing. Initial yields were 6-15 pmol with repetitive yields of better than $85 \%$.

\section{RESULTS}

Detection of immunoreactive HRG in human colostrum and milk. Both human colostrum and milk were found to contain immunoreactivity consistent with the presence of HRG. A total of 42 different samples of colostrum and milk were screened from a total of 24 different lactating mothers; most were positive for the presence of HRG. The immuno dot blots shown in Figure 1 are representative of these samples. The concentrations of HRG were higher in colostrum than in milk; HRG levels were barely detectable in some milk samples obtained after d 3 of lactation. The quantities of immunoreactive $H R G$ detected in either colostrum or milk samples did not differ whether collected in the absence (Fig. $1 A$ ) or presence (Fig. $1 B$ ) of multiple protease inhibitors (aprotinin, soybean trypsin inhibitor, leupeptin, benzamidine, PMSF, TPCK, and EDTA). Large differences in the quantity of immunoreactive HRG were observed, however, in samples of colostrum collected at the same time from different mothers. The quantities of HRG in both colostrum and milk were well below the levels of HRG found in normal adult human plasma (Fig. $1 B$ ); they were also below the levels of $H R G$ detected in plasma from pregnant women at the time of parturition (40$50 \mu \mathrm{g} / \mathrm{mL}$ ).

To establish that we were not observing false-positives, that is, that the nitrocellulose membrane used for the immunoblot analyses had been blocked properly, we compared the use of BSA (3\%) with horse myoglobin $(0.1 \%)$ to eliminate nonspecific Ig binding sites on the membrane. Control immunoblots performed with sample and secondary antibody only (no primary antibody) or primary and secondary antibody only (no antigen) were

A

Colostrum
Colostrum (control)
Milk
Milk (controi)
Plasma (1:640)
Primary + Secondary antibody
Secondary antibody
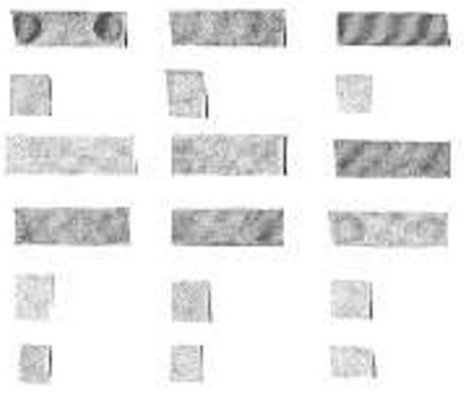

B

Milk: Day of collection

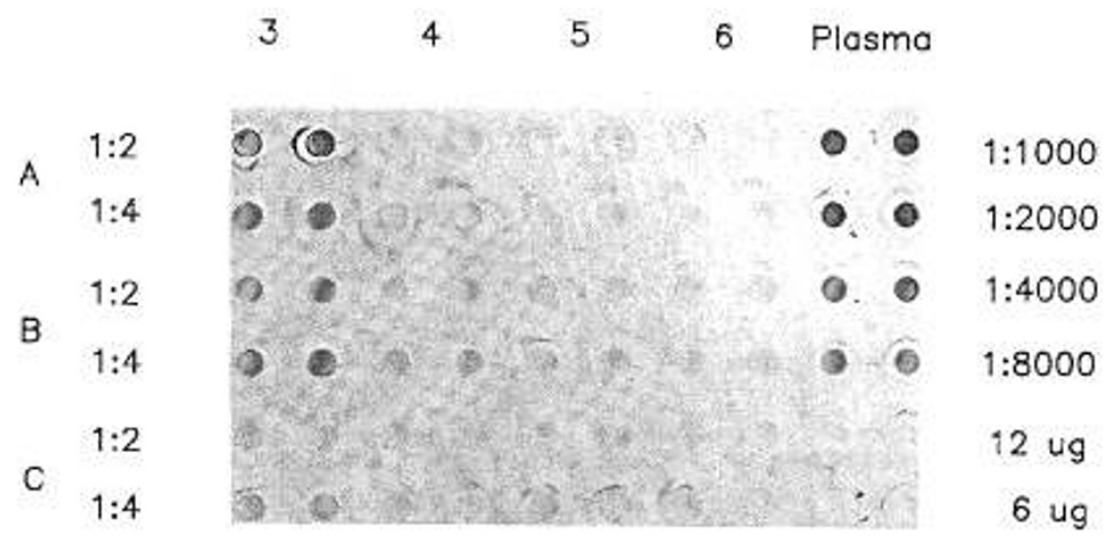

hLf

Fig. 1. Immunodot blot analyses of $\mathrm{HRG}$ in human colostrum and milk. Purified rabbit serum Ig directed against human plasma $\mathrm{HRG}$ were used as primary antibodies to detect immunoreactive (HRG) proteins and peptides in the skim fraction of colostrum (four individuals; rows $I$ and 2), mature milk (eight individuals; rows 3 through 6) collected in the absence (panel A) of protease inhibitors as outlined in Materials and Methods. Negative control blots for the samples of colostrum (row 2) and milk (rows 5 and 6 ) were performed without the primary antibody. Positive control blots included diluted samples of maternal plasma (row 7); negative controls for this sample included blots without antigen (row 8 ) and blots with secondary antibody only (row 9). Panel $B$ shows results observed with colostrum/milk (d 3-6) from three different mothers $(A-C)$ analyzed at two different dilutions (1:2 and 1:4). The right two columns show the reaction intensity observed with samples from our adult plasma pool at several dilutions (1:1000 to 1:8000). The bottom right blots show the limited reaction observed with purified human lactoferrin $(6 \mathrm{and} 12 \mu \mathrm{g})$. 
negative (Fig. $1 A$ ); purified human milk lactoferrin (6 to $12 \mu \mathrm{g}$ ) was also negative (Fig. $1 B$ ).

Samples of colostrum and milk were screened with two different sources of antibodies (goat and rabbit) raised against human plasma HRG purified by two completely different procedures; immobilized $\mathrm{Zn}(\mathrm{II})$ ion affinity chromatography (33) and a combination of ion-exchange methods (e.g. 17). In each case, antibodies specific for HRG were purified from the crude antisera by thiophilic adsorption followed by adsorption on affinity columns of immobilized human plasma HRG. It was evident from the negative dot-blot reactions observed for some of the milk samples (e.g. collected on the 5th and 6th $\mathrm{d}$ of lactation) that the two major proteins in human colostral whey, lactoferrin and $\mathrm{Ig}$, did not react with the anti-HRG antibodies (Fig. 1B). Because of our need for increased sensitivity and accuracy to document the quantities of HRG present in colostrum and milk, purified anti-HRG antibodies were used to develop an enzyme-linked immunosorbent sandwich assay.

Quantitation of $H R G$ in plasma, colostrum, and milk by ELISA. Representative results obtained from our quantitative direct ELISA are presented in Figure 2. The immunoreactivities in serial dilutions of the purified HRG standard protein, pooled plasma from normal adult males, plasma, colostrum, and milk from two early-stage lactating subjects are shown together for reference (Fig. $2 A$ ). We found that the plasma concentrations of $\mathrm{HRG}$ in early-stage lactating women were 50 to $75 \%$ of those in normal adults $(\sim 100 \mu \mathrm{g} / \mathrm{mL})$; our findings were similar to other published results (19). Interference with HRG immunoreactivity in milk was suggested by the apparent increase in signal intensity upon increased sample dilution. Direct evidence for the ability of components in both colostrum and milk to depress the apparent immunogenicity of HRG is presented in Figure $2 B$. Samples of both colostrum and milk were analyzed in parallel with and without an added $10 \mathrm{ng}$ of purified human plasma HRG. Immunoreactivity was depressed significantly at less than a 500- to 1000 -fold dilution. Therefore, the quantities of $H R G$ in some samples of colostrum and milk were possibly underestimated by ELISA methods. However, in some milk samples collected on the 2 nd or $3 \mathrm{rd} d$ of lactation, concentrations of HRG were relatively high and inhibition of immunoreactivity with antiHRG antibodies was relatively low; the estimated HRG concentration in these samples ranged from 0.13 to $10 \mu \mathrm{g} / \mathrm{mL}(2.8 \pm$ $3.6 \mu \mathrm{g} / \mathrm{mL}, n=9$ ). In milk samples collected between the 5 th and $15 \mathrm{th} \mathrm{d}$ of lactation, the estimated concentration of $\mathrm{HRG}$ ranged from 0.1 to $10 \mu \mathrm{g} / \mathrm{mL}(2.75 \pm 3.7 \mu \mathrm{g} / \mathrm{mL}, n=11)$. Thus, the concentration of HRG in colostrum and milk was similar, and that amount was approximately $5 \%$ of the HRG concentration in the plasma (of the same subjects). Human milk lactoferrin $(10 \mu \mathrm{g})$ showed no evidence of immunoreactivity in this assay. We next attempted to circumvent problems with the immunodetection of HRG in crude samples because of possible occlusion of immunoreactive sites, which may result from the association of HRG with other milk components under nondenaturing conditions.

Molecular forms of HRG present in colostrum and milk. HRG in adult human serum interacts with a wide variety of proteins and ligands (5-13) and is also very sensitive to proteolytic attack and degradation (33). Radial immunodiffusion suggested the presence of multiple forms of immunoreactive HRG in both colostrum and milk samples; double rings were observed (in contrast to the single ring observed for plasma or purified $\mathrm{HRG}$ standards). Thus, the molecular forms of fully denatured HRG (i.e. immunoreactive peptides and proteins) in colostrum and milk were examined by SDS-PAGGE followed by Western transfer to nitrocellulose and immunoblot analyses with purified antihuman HRG antibodies. The data in Figure 3 demonstrate the presence of a 74-kD protein in colostrum that was recognized by the purified anti-human HRG antibodies from the two sources. The 74-kD protein in colostrum and milk retained its immunoreactivity after denaturation both in the absence (panel $A$ ) and
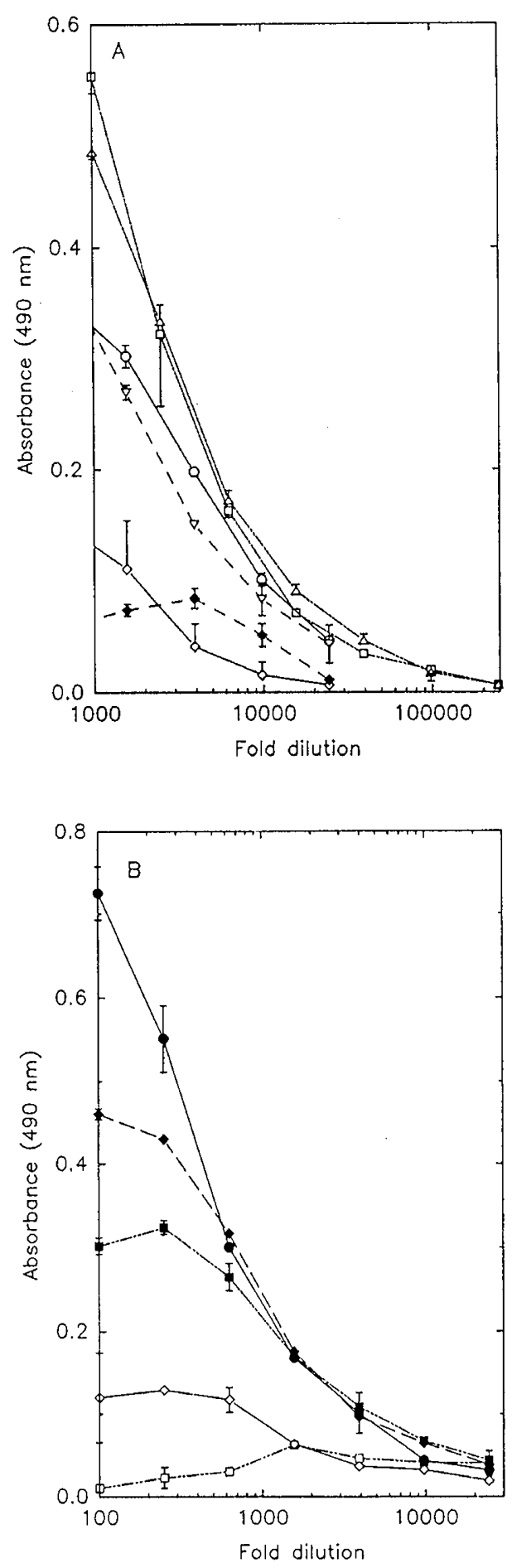

Fig. 2. Quantitation of HRG in human colostrum and milk by the ELISA method. Panel $A$ shows serial dilutions (2.5-fold each) of purified human plasma HRG standard ( $100 \mu \mathrm{L}$ of a $1-\mathrm{mg} / \mathrm{mL}$ solution per well; open squares), pooled adult male plasma (open triangles), plasma from two different lactating women (open circles and inverted triangles), d-2 to -3 colostrum (open diamonds), and d- 8 milk (closed diamonds) from the same subject. Panel $B$ shows serial dilutions of purified human plasma HRG (100 $\mu \mathrm{L}$ of a 1-mg/mL solution; closed circles), d-2 colostrum with (closed diamonds) and without (open diamonds) $10 \mathrm{ng}$ of added HRG, and d- 6 milk with (closed squares) and without (open squares) $10 \mathrm{ng}$ of added HRG. All values are shown as means $\pm \mathrm{SD}$. 


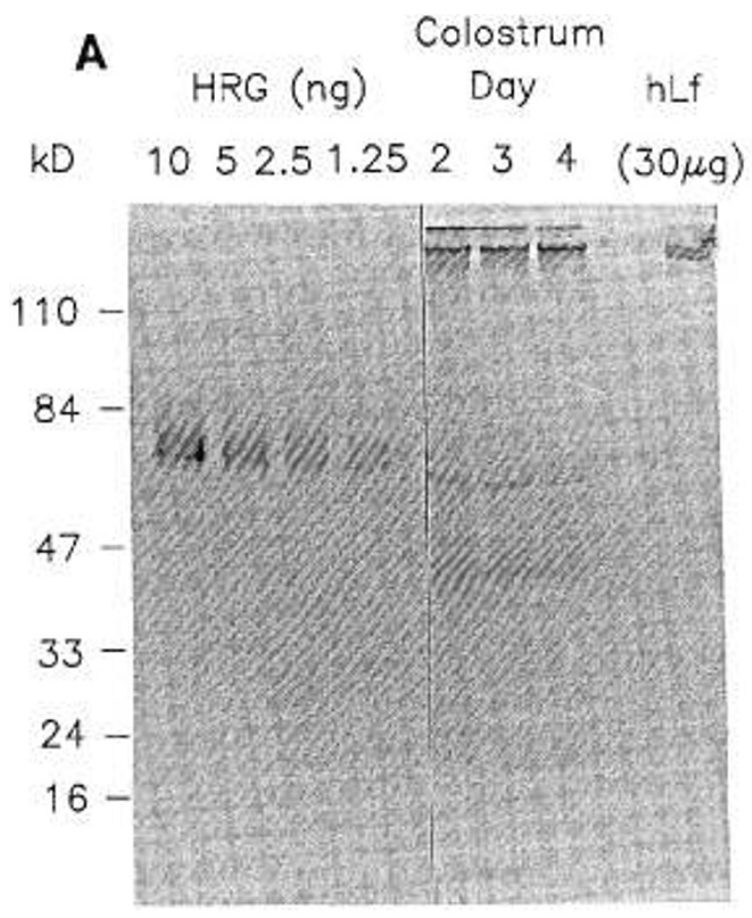

B

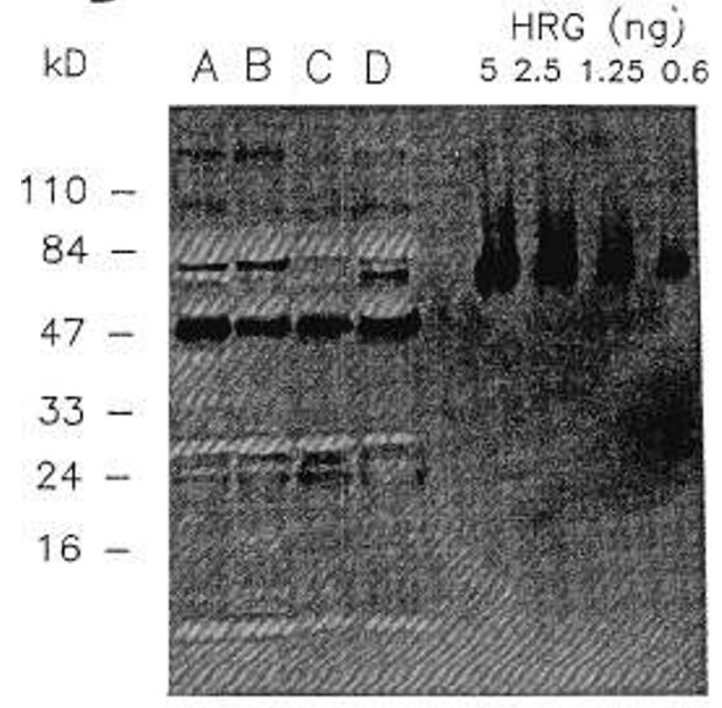

Fig. 3. SDS-PAGGE and immunoblot analyses of HRG in colostrum $/$ milk. Milk samples analyzed in panel $A$ were collected from the same subject (lactation d 2-4) without added protease inhibitors and were denatured under nonreducing conditions. The immunoblot reaction intensities of the HRG in the milk samples ( $5 \mu \mathrm{L} /$ lane) were compared with those of purified human plasma HRG (10-1.2 ng). Detection was by the alkaline phosphatase-catalyzed color reaction described in Materials and Methods. Immunoblot analyses of whole colostrum (lactation d 2-3) collected (in the presence of protease inhibitors) from four different subjects $(A-D)$ is presented in panel $B$ under denaturing and reducing conditions. The immunoblot was developed with the enhanced chemiluminescence detection system as described in Materials and Methods. The immunoblot reaction intensities of the HRG in the colostral samples ( $3 \mu \mathrm{L} / \mathrm{lane}$ ) were compared with those of purified human plasma HRG $(5-0.6 \mathrm{ng})$. Lactoferrin $(30 \mu \mathrm{g})$ was included as a negative control ( panel $A$ ). Details are provided in Materials and Methods. presence ( panel $B$ ) of reducing reagent. Based upon estimates from the analysis of 59 samples from 22 individuals, the $74-\mathrm{kD}$ band varied from approximately $0.03 \mu \mathrm{g} / \mathrm{mL}$ to $0.4 \mu \mathrm{g} / \mathrm{mL}$. The bands of HRG immunoreactivity in colostrum and early milk were sharper and displaced to a slightly lower position than observed with purified standard HRG, most likely because the much larger concentration of lactoferrin $(78 \mathrm{kD})$ in these samples distorted the band of HRG immunoreactivity. In addition to the 74-kD protein band detected by immunoblotting, bands of immunoreactive protein at a significantly higher molecular mass $(>110 \mathrm{kD})$ were observed under nonreducing conditions (Fig. $3 A$ ). These high molecular mass species of $\mathrm{HRG}$ immunoreactivity were not observed in samples of human plasma (data not shown). Even when colostrum and milk samples were collected in the presence of multiple protease inhibitors and EDTA, immunoreactive proteins and peptides of lower molecular mass $(47,24$, and $12-14 \mathrm{kD})$ were observed in various relative ratios (Fig. $3 B$ ). These lower molecular mass species were present after denaturation under both reducing and nonreducing conditions; the $47-$ and $24-\mathrm{kD}$ bands were more intense if the samples were reduced. Finally, the addition of purified human milk Ig to our purified anti-HRG antibodies did not eliminate the recognition of probable $\mathrm{HRG}$ fragments at 47 and $24 \mathrm{kD}$. The existence of multiple forms of HRG corroborated with the observation of two precipitin lines by radial immunodiffusion (data not shown).

Lactoferrin is the major whey protein with a mass $(78 \mathrm{kD})$ similar to that of HRG. Thus, the interaction of our purified anti-HRG antibodies with human milk lactoferrin (e.g. $30 \mu \mathrm{g})$ was evaluated routinely; there was consistently no evidence of immunoreactivity in this assay. In separate experiments, secretory $\operatorname{IgA}$, another major human milk protein, was also found not to react with the anti-HRG antibodies both in the presence and absence of reducing agents.

Isolation of HRG from human milk. Two separate protein isolation methods were attempted to purify HRG from human milk. First, immunoaffinity isolation methods were used to partially purify $H R G$. Anti-HRG antibodies were highly purified on columns of immobilized HRG. Affinity columns of immobilized, purified, anti-human plasma $\mathrm{HRG}$ antibodies were then used to isolate HRG from several samples of human colostrum and milk. Representative results from six separate affinity isolation experiments are presented in Figure 4. Both the 74- (again slightly displaced as explained earlier) and the $47-\mathrm{kD}$ forms of $\mathrm{HRG}$ were present in the starting sample (lane $S S$ of immunoblot). Little or no HRG immunoreactivity was observed in the affinity column flow-through fractions (lane I). Washing the immobilized antibody-bound HRG with $3 \mathrm{M}$ urea (lane $I I$ ) eluted a large spectrum of both high and low molecular mass proteins, but little or no immunoreactive $H R G$ at $74 \mathrm{kD}$ was eluted; some immunoreactivity at the $47-\mathrm{kD}$ band was, however, eluted. Elution with $25 \%$ ethylene glycol to diminish hydrophobic interactions (lane III) did not remove HRG or HRG-associated proteins. Some HRG-associated proteins, including lactoferrin, were eluted with $2.5 \mathrm{M} \mathrm{NaCl}$ (lane IV). Little or no protein, including intact HRG, was observed upon elution with pH 2.5 glycine buffer (lane $V$ ), although some of the $47-\mathrm{kD}$ form was eluted. Finally, several proteins were coeluted with the immunoreactive HRG band (mostly the 74-kD form) by adding $2 \mathrm{M}$ sodium thiocyanate to the affinity column (lane VI). Results from at least six similar affinity isolation experiments with immobilized anti-human HRG antibodies also suggested the association of human milk HRG with other proteins. Thus, an entirely different method of HRG isolation was attempted. This new affinity isolation method is based upon the use of immobilized $\mathrm{Zn}$ (II) ions and has been used successfully to purify intact HRG from human plasma (33).

The gel electrophoresis profile shown in Figure $5 \mathrm{~A}$ illustrates, by silver staining, the number of human milk proteins recovered from an affinity column of immobilized TED-Zn(II) ions. Separate immunoblots of this same sample (same gel) with anti- 
A

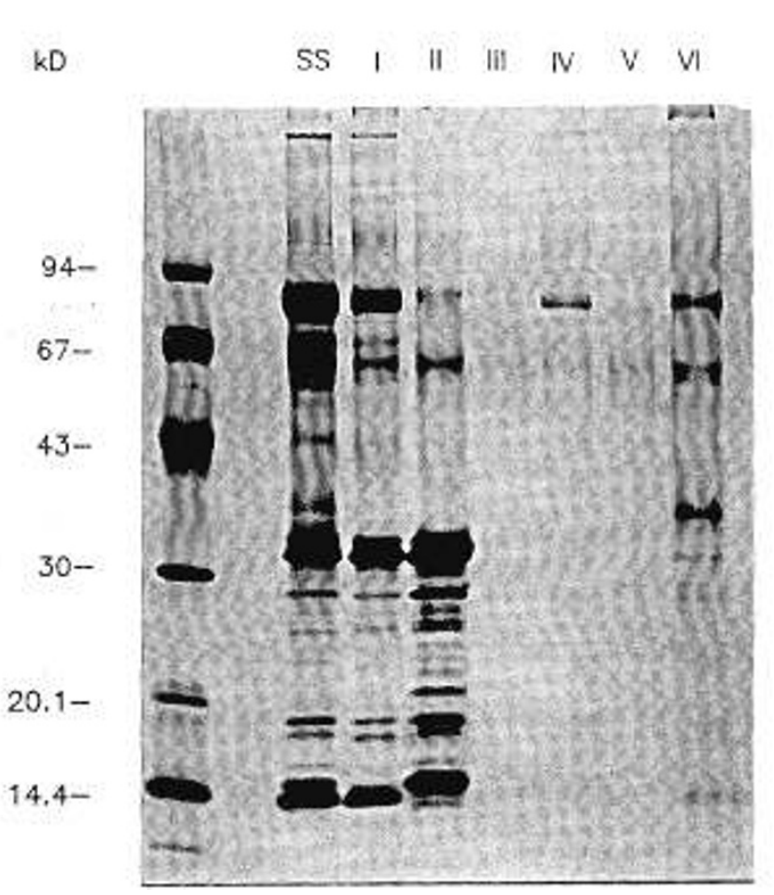

B

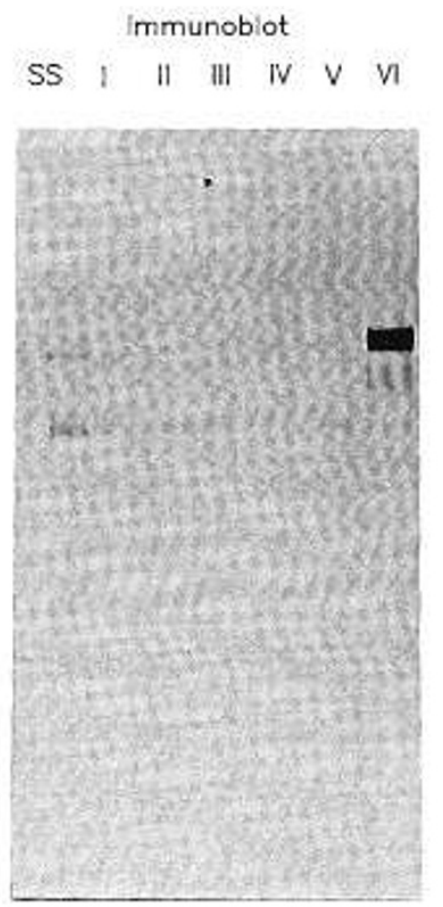

Fig. 4. Human milk proteins copurified with HRG on affinity columns of purified, immobilized anti-HRG antibodies. Panel $A$ shows the silverstained pattern of proteins observed by SDS-PAGGE before and after each step in the purification procedure; panel $B$ shows the anti-HRG immunoblots of these same samples. The molecular mass marker proteins are shown in lane 1. From left to right are shown an aliquot of the starting sample of colostrum $(S S)$, the unadsorbed proteins in the flow-through fraction of the immobilized anti-HRG affinity column $(I)$, proteins eluted from the affinity column with $3 \mathrm{M}$ urea (II), proteins eluted with $25 \%$ ethylene glycol (III), proteins eluted with $2.5 \mathrm{M} \mathrm{NaCl}(I V)$, proteins eluted with $0.1 \mathrm{M}$ glycine pH $2.5(\mathrm{~V})$, and proteins eluted with $2 \mathrm{M}$ sodium thiocyanate $(V I)$. Experimental details are provided in Materials and Methods.

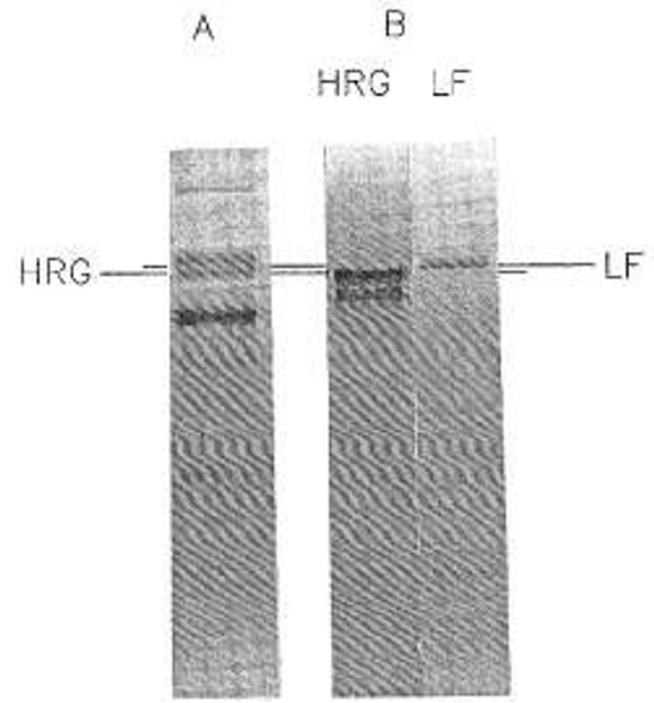

Fig. 5. SDS-PAGE and immunoblots of human milk proteins, including HRG, partially purified on affinity column of immobilized TED$\mathrm{Zn}(\mathrm{II})$. Panel $A$ shows the silver-stained pattern of adsorbed human milk proteins. Panel $B$ shows the identification of $H R G$ and lactoferrin by immunoblot analyses with purified anti-HRG antibodies and anti-lactoferrin antibodies (see lines) as described in Materials and Methods. Similar gels were electroblotted onto polyvinylidinedifluoride membranes for amino acid sequence analyses of the $74-\mathrm{kD}$ protein recognized by the anti-HRG antibodies (see Table 1).
HRG and anti-lactoferrin antibodies revealed the presence of HRG immunoreactivity and lactoferrin. In Figure 5, the panel $B H R G$ lane was blotted with anti-HRG antibodies. The panel $B L F$ lane of Figure 5 was the same sample blotted with antilactoferrin antibodies. Because lactoferrin, by itself, did not bind to the immobilized TED-Zn(II) column, these data (i.e. the coelution of HRG and lactoferrin) suggest the interaction of lactoferrin with HRG. The identities of the other proteins copurified with HRG (Fig. $5 A$ ) are not yet known.

$N$-terminal amino acid sequence analyses of $H R G$ isolated. from human milk. N-terminal amino acid sequence analyses (obtained in triplicate) of the $74-\mathrm{kD}$ protein band that was recognized by the anti-HRG antibodies (Fig. $5 B$ ) provided further evidence of its identity as HRG; 13 of the first 15 residues were identical to human HRG (Table 1).

\section{DISCUSSION}

Our results first demonstrated the presence of HRG or an antigenically similar protein in human colostrum and mature milk. One form of the immunoreactive protein appeared to have a molecular mass identical to that observed previously for the intact HRG isolated from adult human plasma $(3,4)$. The

Table 1. $N$-terminal amino acid sequence anlaysis of $74-k D$ protein with HRG immunoreactivity isolated from human milk by immobilized TED-Zn(II) ion affinity adsorption*

\begin{tabular}{llll}
\hline & 1 & 6 & 11 \\
Human milk & VSPTD & XSAVE & PXAEK \\
Human plasma & VSPTD & CSAVE & PEAEK . . . \\
\hline
\end{tabular}

* The amino acid sequence for human plasma $H R G$ was derived from the cDNA sequence described by Koide et al. (4). X designates amino acid residues that we were unable to identify. 
identity of the immunoreactive 74-kD protein was supported by analysis of its N-terminal amino acid sequence; 13 of the first 15 residues were identical to human HRG (the other two residues were not different, they were undetected). Further biophysical analyses will require purification (to homogeneity) of the intact 74-kD protein from human milk and colostrum. Our preliminary efforts with affinity columns of immobilized anti-HRG antibodies and immobilized $\mathrm{Zn}$ (II) ions have suggested to us that purification of intact HRG from human milk will be much more difficult than its purification from plasma.

The presence of immunoreactive proteins at 47, 24, and 12$14 \mathrm{kD}$ in milk is most likely a reflection of the documented (at least for plasma HRG) sensitivity of this protein to proteolytic processing or breakdown. These immunoreactive bands, however, were present even in human milk and colostrum collected with reportedly adequate concentrations of protease inhibitors $(9,34,35)$. Very similar HRG degradation products have been observed after treatment of purified plasma HRG with plasmin or trypsin $(8,34)$. The inclusion of multiple protease inhibitors (e.g. aprotinin, TPCK, PMSF, and soybean trypsin inhibitor) and EDTA did not entirely prevent this process. Although it is certainly possible, several results suggest that the lower molecular weight immunoreactive bands $(47,24$, and $12-14 \mathrm{kD})$ do not represent artifacts of cross-reactivity. First, our anti-HRG antibodies were purified by affinity adsorption to a homogeneous preparation of human plasma HRG purified without the use of antibodies (33). The most likely milk proteins, other than HRG fragments, to be present at 47 and $24 \mathrm{kD}$ under the denaturing conditions used for SDS-PAGGE would be the heavy and light chains of the Ig. Despite the continuous presence of Ig in milk, several milk samples were negative for $H R G$ immunoreactivity. Also, even though Ig are present in human plasma, the 47- and 24-kD bands of HRG immunoreactivity observed in milk were not typically observed on HRG blots of plasma proteins under nonreducing conditions (33). Furthermore, in separate experiments, we performed the HRG immunoblots using purified antiHRG antibodies that had been preincubated with an excess ( 2 $\mathrm{mg} / \mathrm{mL}$ ) of isolated human milk Ig; the 47- and 24-kD immunoreactive $H R G$ bands were still observed. If our interpretation is correct, the regulation and biologic consequence of this proteolytic processing are presently unknown. We do not presently have an interpretation for the HRG immunoreactive milk protein migrating on denaturing SDS gels at $>110 \mathrm{kD}$. It may represent cross-reactivity due to the presence of a structurally related surface domain. Identification by $\mathrm{N}$-terminal amino acid sequencing was unsuccessful due to a blocked terminus.

The N-terminal portion of adult human plasma HRG has been shown to be homologous in sequence to antithrombin III (7). Furthermore, several of the isolated peptide fragments have been shown to have preserved heme- and metal-binding properties $(36,37)$. The C-terminal $14-\mathrm{kD}$ fragment of serum $\mathrm{HRG}$ is exceptionally rich in protein content. The possible relationship of this portion of HRG to the proline-rich polypeptide also found in milk is intriguing, especially given the reported immunemodulating activities attributed to proline-rich polypeptide (38$42)$. Given the recent implication that $H R G$ plays a role in regulating $T$-lymphocyte activation $(35,43)$, it may be important to elucidate both the structural and functional integrity of $H R G$ in milk, as well as its metabolic fate in infants fed human milk.

The serum HRG protein is believed to be synthesized by liver cells (4). The origin of the HRG discovered in human milk, however, has not yet been investigated. A dramatic decrease in the concentration of HRG after the initial 2-3 d of lactation might suggest that it comes from plasma. We have not found this to be so, however, on the basis of both ELISA and immunoblots of SDS-polyacrylamide gels of colostrum and milk. We are attempting to confirm the origin of the HRG colostrum and milk by using techniques that include radiolabeled cDNA hybridization and the incorporation of stable isotopes into newly synthesized plasma and milk proteins.
HRG is involved in an assortment of biologic activities. Its metabolic fate in human milk-fed infants, therefore, is of interest. Human milk-fed preterm infants, in particular, have been shown capable of absorbing 74- to $78-\mathrm{kD}$ proteins (i.e. lactoferrin) in their intact form (44-46). We have documented the presence of immunoreactive $H R G$ in the urine of preterm infants fed human milk (Hutchens TW, Yip T-T, unpublished data). If a significant quantity of urinary $H R G$ is maternal in origin, HRG may influence infant development through the variety of enzymatic and immunoregulatory properties that have been attributed to its presence.

The presence of HRG in human colostrum and milk suggests that this high capacity metal-binding protein might be among the proteins that participate in the bioavailability of divalent metal cations. The specific contribution of $H R G$ in this regard, if any, remains to be established. Although it is difficult to eliminate metal ion exchange during analysis of intermediate affinity metal-binding components, we are currently comparing the in vitro metal-binding properties of $H R G$ with those of other components isolated from human colostrum and milk.

If $\mathrm{HRG}$ does prove to be important in infant development, it may confer some benefit on breast-fed infants that might be absent from formula-fed infants. A similar investigation of $H R G$ and its metal-binding fragments in bovine milk is needed. Analysis of bovine milk by SDS-PAGGE, Western transfer, and immunoblotting with anti-human HRG indicated the presence of HRG (or an antigenically related protein) in bovine colostrum and milk. Purification of bovine plasma HRG by immunosorbent affinity chromatography and verification of its identity by $\mathrm{N}$-terminal sequence analysis has recently been accomplished (Yip T-T, Hutchens TW, unpublished data). As specific antibovine HRG antibodies become available, we will 1) continue our investigation of HRG in bovine milk and bovine milk-based formulas and 2) begin our investigation of the metabolic fate of this protein (and bound metal ions) in the gastrointestinal tract of both preterm and term infants.

Acknowledgments. The authors thank J. Scott Magnuson, Christine Yip, and Gary L. Cook in our laboratory for their assistance with these investigations. We thank Judy M. Hopkinson and her staff in our Metabolic Research Unit for their help in the collection of human colostrum and milk, Ann Smith for her helpful comments and suggestions, and Jerry D. Eastman in our publications department for his editorial assistance during the preparation of this manuscript.

\section{REFERENCES}

1. Brock JH 1985 Transferrins. In: Harrison P (ed) Metalloproteins. Part 2: Metal Proteins with Non-Redox Roles. Topics in Molecular and Structural Biology, Series, Vol 7. Verlag Chemie, Basel, Switzerland, pp 183-262

2. Lonnerdal B 1985 Biochemistry and physiological function of human milk proteins. Am J Clin Nutr 42:1299-1317

3. Heimburger N, Haupt H, Kranz T, Baudner S 1972 Humanserumproteine mit hoher affinitat zu carboxymethylcellulose, II. Hoppe-Seyler Z Physiol Chem 353:1133-1140

4. Koide T, Foster D, Yoshitake S, Davie EW 1986 Amino acid sequence of human histidine-rich glycoprotein derived from the nucleotide sequence of its cDNA. Biochemistry 25:2220-2225

5. Morgan WT 1978 Human serum histidine-rich glycoprotein I. Interactions with heme, metal ions and organic ligands. Biochim Biophys Acta 533:319333

6. Lijnen HR, Hoylaerts M, Collen D 1980 Isolation and characterization of a human plasma protein with affinity for the lysine binding sites in plasminogen. J Biol Chem 255:10214-10222

7. Koide $\mathrm{T}$, Odani S, Ono $\mathrm{T} 1982$ The $\mathrm{N}$-terminal sequence of human plasma histidine-rich glycoprotein homologous to antithrombin with high affinity for heparin. FEBS Lett 141:222-224

8. Morgan WT 1985 The histidine-rich glycoprotein of serum has a domain rich in histidine, proline, and glycine that binds heme and metals. Biochemistry 24:1496-1501

9. Koide T, Odani S, Ono T 1985 Human histidine-rich glycoprotein: Simultaneous purification with antithrombin III and characterization of its gross structure. J Biochem 98:1191-1200

10. Peterson CB, Morgan WT, Blackburn MN 1987 Histidine-rich glycoprotein 


\section{HUTCHENS ET AL.}

modulation of the anticoagulant activity of heparin. J Biol Chem 262:75677574

11. Lerch PG, Nydegger UE, Kuyas C, Haeberli A 1988 Histidine-rich glycoprotein binding to activated human platelets. Br J Haematol 70:219-224

12. Leung L, Saigo K, Grant D 1989 Heparin binds to human monocytes and modulates their procoagulant activities and secretory phenotypes. Effect of histidine-rich glycoprotein. Blood 73:177-184

13. Shimada K, Kawamoto A, Matsubayashi K, Ozawa T 1989 Histidine-rich glycoprotein does not interfere with interactions between antithrombin III and heparin-like compounds on vascular endothelial cells. Blood 73:191193

14. Loomis RE, Tseng CC, Levine MJ 1988 N.M.R. analyses of the histidine microenvironments in a human proline-rich glycoprotein. Int J Pept Protein Res 32:123-129

15. Gurd FRN, Wilcox PE 1956 Complex formation between metallic cations and proteins, peptides, and amino acids. Adv Protein Chem 11:311-427

16. Hemdan ES, Zhao Y-J, Sulkowski E, Porath J 1989 Surface topography of histidine residues: a facile probe by immobilized metal ion affinity chromatography. Proc Natl Acad Sci USA 86:1811-1815

17. Morgan WT 1981 Interactions of the histidine-rich glycoprotein of serum with metals. Biochemistry 20:1054-1061

18. Guthans SL, Morgan WT 1982 The interaction of zinc, nickel and cadmium with serum albumin and histidine-rich glycoprotein assessed by equilibrium dialysis and immunoadsorbent chromatography. Arch Biochem Biophys 218:320-328

19. Morgan WT, Koskelo P, Koenig H, Conway TP 1978 Human histidine-rich glycoprotein II. Serum levels in adults, pregnant women and neonates. Proc Soc Exp Biol Med 158:647-651

20. Haukkamaa M, Morgan WT, Koskelo P 1983 Serum histidine-rich glycoprotein during pregnancy and hormone treatment. Scand J Clin Lab Invest 43:591-595

21. Omri A, Kruithof EKO, Bachmann F 1988 Histidine-rich glycoprotein during pregnancy. Thromb Haemost 59:341

22. Corrigan Jr JJ, Jeter MA 1990 Histidine-rich glycoprotein and plasminogen plasma levels in term and preterm infants. Am J Dis Child 144:825-828

23. Widdowson EM 1974 Trace elements in foetal and early postnatal development. Proc Nutr Soc 33:275-284

24. Shaw JCL 1979 Trace elements in the fetus and young infant. I. Zinc. Am J Dis Child 134:74-81

25. Evans GW, Johnson PE 1980 Characterization and quantitation of a zincbinding ligand in human milk. Pediatr Res 14:876-880

26. Fransson G-B, Lonnerdal B 1982 Zinc, copper, calcium, and magnesium in human milk. J Pediatr 101:504-508

27. Fransson G-B, Lonnerdal B 1983 Distribution of trace elements and minerals in human and cow's milk. Pediatr Res 17:912-915

28. Casey CE, Hambidge KM, Neville MC 1985 Studies in human lactation: zinc, copper, manganese and chromium in human milk in the first month of lactation. Am J Clin Nutr 41:1193-1200

29. Blakeborough P, Gurr MI 1986 Digestion of the zinc in human milk, cow's milk and a commercial babyfood: some implications for human infant nutrition. Br J Nutr 55:209-217
30. Butte NF, Garza C, Smith EO, Wills C, Nichols BL 1987 Macro- and tracemineral intakes of exclusively breast-fed infants. Am J Clin Nutr 45:42-48

31. Hutchens TW, Porath J 1986 Thiophilic adsorption of immunoglobulins: analysis of conditions optimal for selective immobilization and purification. Anal Biochem 159:217-226

32. Magnuson JS, Henry JF, Yip T-T, Hutchens TW 1990 Structural homology of human, bovine, and porcine milk lactoferrins: evidence for shared antigenic determinants. Pediatr Res 28:176-181

33. Yip TT, Hutchens TW 1991 Metal ion affinity adsorption of a $\mathrm{Zn}$ (II)-transport protein present in maternal plasma during lactation: structural characterization and identification as histidine-rich glycoprotein. Protein Expression and Purification 2:355-362

34. Smith A, Nuiry I, Morgan WT 1985 Proteolysis of histidine-rich glycoprotein in plasma and in patients undergoing thrombolytic therapy. Thromb Res 40:653-661

35. Saigo K, Shatsky M, Levitt LJ, Leung LLK 1989 Interaction of histidine-rich glycoprotein with human T lymphocytes. J Biol Chem 264:8249-8253

36. Katagiri M, Tsutsui K, Yamano T, Shimonishi Y, Ishibashi F 1987 Interaction of heme with a synthetic peptide mimicking the putative heme-binding site of histidine-rich glycoprotein. Biochem Biophys Res Commun 149:10701076

37. Morgan WT, Deaclue V, Riehm JP 1989 A heme- and metal-binding hexapeptide from the sequence of rabbit plasma histidine-rich glycoprotein. J Mol Recog 2:122-125

38. Robinson R, Kauffman DL, Waye MM, Blum M, Bennick A, Keller PJ 1989 Primary structure and possible origin of the non-glycosylated basic prolinerich protein of human submandibular/sublingual saliva. Biochem J 263:497503

39. Funakoshi M, Sasaki J, Arakawa K 1988 Proline-rich protein is a glycoprotein and an acute phase reactant. Biochim Biophys Acta 963:98-108

40. Zimecki M, Pierce CW, Janusz M, Weiczorek Z, Lisowski J 1987 Proliferative response of $\Upsilon$ lymphocytes to a proline-rich polypeptide (PRP): PRP mimics mitogenic activity of Il-1. Arch Immuno Ther Exp (Warsz) 35:339-349

41. Julius MH, Janusz M, Liskowski J 1988 A colostral protein that induces the growth and differentiation of resting B lymphocytes. J Immunol 140:13661371

42. Janusz M, Weiczorek Z, Spiegel K, Kubik A, Szewczuk Z, Siemion I, Lisowski J 1987 Immunoregulatory properties of synthetic peptides, fragments of a proline-rich polypeptide (PRP) from ovine colostrum. Mol Immunol 24:1029-1031

43. Shatsky M, Saigo K, Burdach S, Leung LLK 1989 Histidine-rich glycoprotein blocks $T$ cell rosette formation and modulates both $T$ cell activation and immunoregulation. J Biol Chem 264:8254-8259

44. Hutchens TW, Henry JF, Yip TT 1989 Purification of intact lactoferrin found in the urine of human milk-fed preterm infants. Clin Chem 35:1928-1933

45. Hutchens TW, Henry JF, Yip T-T, Hachey D, Schanler RJ, Motil K, Garza C 1991 Origin of intact lactoferrin found in the urine of human milk-fed preterm infants. Evaluation by stable isotopic enrichment. Pediatr Res 29:243-250

46. Hutchens TW, Henry JF, Yip TT 1991 Structurally intact ( $78 \mathrm{kDa}$ ) forms of maternal lactoferrin purified from the urine of preterm infants fed human milk: identification of a trypsin-like proteolytic cleavage event in vivo that does not result in fragment dissociation. Proc Natl Acad Sci USA 88:29942998 